\section{EMBRYRIDDLE \\ Aeronautical University}

SCHOLARLY COMMONS

\section{International Journal of Aviation,} Aeronautics, and Aerospace

\title{
Flight Simulator Fidelity, Training Transfer, and the Role of Instructors in Optimizing Learning
}

\author{
Paul L. Myers III \\ Embry-Riddle Aeronautical University, myersiip@erau.edu \\ Arnold W. Starr \\ Embry-Riddle Aeronautical University, starrira@my.erau.edu \\ Kadie Mullins \\ Embry-Riddle Aeronautical University, haywardk@erau.edu
}

Follow this and additional works at: https://commons.erau.edu/ijaaa

Part of the Cognition and Perception Commons, Curriculum and Instruction Commons, and the Educational Psychology Commons

\section{Scholarly Commons Citation}

Myers, P. L., Starr, A. W., \& Mullins, K. (2018). Flight Simulator Fidelity, Training Transfer, and the Role of Instructors in Optimizing Learning. International Journal of Aviation, Aeronautics, and Aerospace, 5(1). https://doi.org/10.15394/ijaaa.2018.1203

This Literature Review is brought to you for free and open access by the Journals at Scholarly Commons. It has been accepted for inclusion in International Journal of Aviation, Aeronautics, and Aerospace by an authorized administrator of Scholarly Commons. For more information, please contact commons@erau.edu. 
On November 12, 2001, American Airlines Flight 587, an Airbus A300, departed from John F. Kennedy International Airport. Shortly after takeoff, the aircraft encountered wake turbulence from a preceding departing aircraft. The aircraft upset caused the copilot flying the aircraft to use excessive rudder input in both directions, over-stressing the rudder and causing it to depart the aircraft (NTSB, 2001; NTSB, 2004a; NTSB, 2004b). All 260 people on the aircraft and five people on the ground were killed and the aircraft was destroyed.

In the mishap report, the National Transportation Safety Board (NTSB) highlighted two contributing factors. Both relate to the simulator training and its fidelity. First, incorrect rudder application was taught by simulator instructors. Second, the rudder pedal responses in the simulator were significantly different from the aircraft. The combination of the two may have caused the copilot to overcontrol, leading to confusion and surprise (NTSB, 2001; NTSB, 2004a; NTSB, 2004b). The rudder input fidelity differences were caused by software misrepresentation of an elastic cable stretch that was less stiff than the cable stretch in the aircraft (NTSB, 2001; NTSB, 2004a; NTSB, 2004b). The differences between the simulator and aircraft are shown in Figure 1.

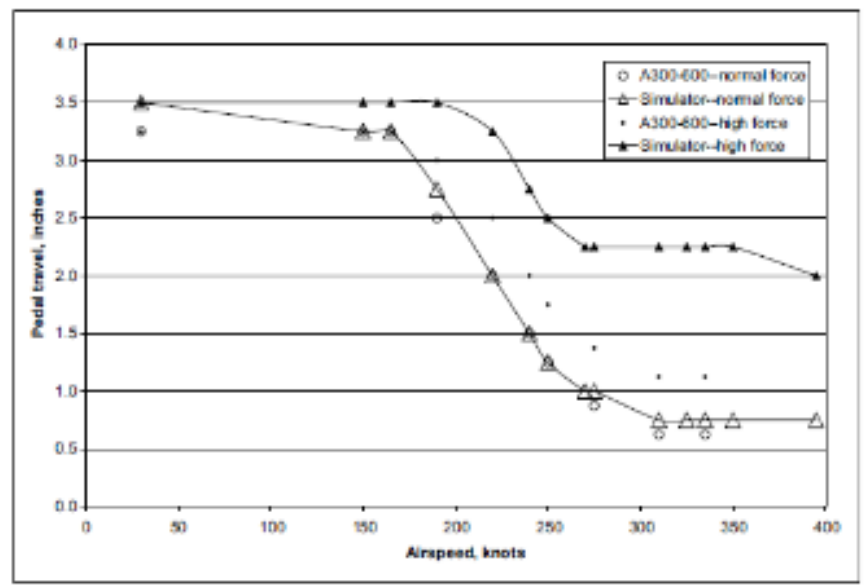

Figure 1. Fidelity differences between simulator and aircraft rudder pedal inputs (Courtesy of the NTSB, 2001).

Fidelity, the degree to which the simulator looks like the real aircraft and the similarity to which it acts like the real aircraft, is closely linked to training transfer. (Allen, Hays, \& Buffardi, 2001; Noble, 2002). Training transfer refers to the process by which knowledge, abilities, or skills acquired through training are applied to the actual situation (Hochmitz, \& Yuviler-Gavish, 2011). Negative training transfer is the dampening effect of previous learning on the exercise of skills or on new learning (Blaiwes, Pug, \& Regan, 2001). The presence of poor 
fidelity may lead to negative training transfer with unsafe, even catastrophic results (Lee, 2009). Numerous mishaps, such as American Airlines Flight 587, can be illustrative of this theory. This paper, therefore, examines the efficacy of both high and low fidelity on training transfer and explores the flight simulator instructor's role in exploiting the simulator's strengths as a training tool while minimizing negative training transfer.

\section{Simulator Training History}

The history of flight simulation dates to 1929 when Edwin Link built his first Link Trainer. The device had a basic set of instruments, a primitive motion platform, and no visual display (Lee, 2009). When World War II began, the Link Trainer was integrated into flight training and used extensively. At the time, training accident rates were quite high and using simulators to reduce the aircraft accident rate was believed to be a logical outcome (Valverde, 1973). The training value of simulators substituting for aircraft was intuitive and based on common sense (Lee, 2009). After the war, rapid simulator progress was achieved due to many technological advancements during the war. Crucial to this evolution was the development of analog computers. However, the academic study of flight simulators did not start until around 1949 (Valverde, 1973). These studies continue in earnest today.

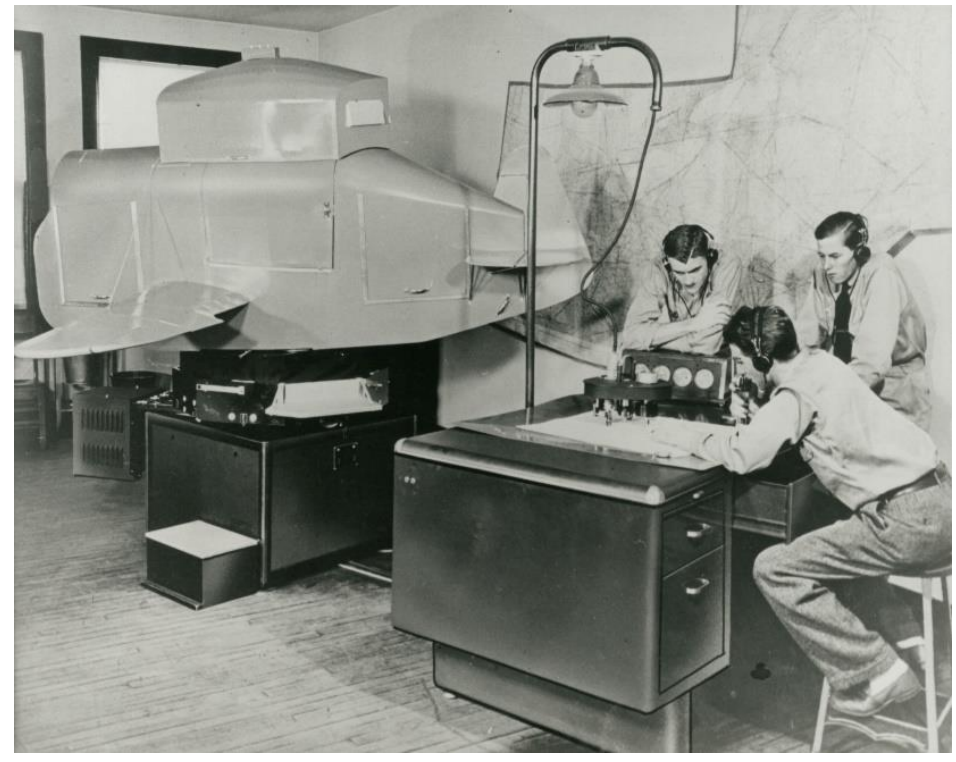

Figure 2. Link Blue Box Trainer.

(https://www.link.com/media/gallery/Link_Blue_Box_Training_2.jpg. Image

Courtesy of L3 Link. Reprinted with permission.) 


\section{Advantages}

Simulators provide several advantages and are integral to modern aviation training programs. These advantages include (a) providing a safe environment to practice potentially dangerous procedures, such as an engine failure or rejected takeoff, that should not or cannot be performed in the aircraft, (b) significantly reducing training costs, (c) producing a positive impact on the environment by way of conservation of resources and reduced carbon footprint, (d) providing a research platform and laboratory, and (e) allowing rapid and multiple repetitions of events, such as instrument approaches and landings (Williges, Roscoe, \& Williges, 2001). These many advantages have resulted in the requirement to use advanced simulators in the FAA's Advanced Qualification Program (Longridge, 1997).

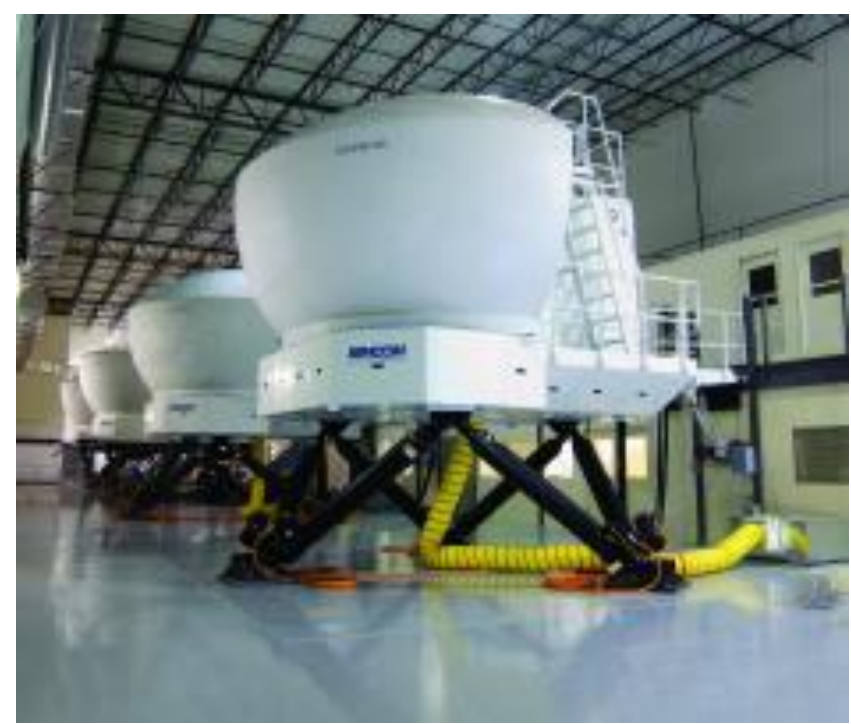

Figure 3. Full Motion Level 3 / 4 Flight Simulators. BART International Simulators at SimCom Training Center. (Retrieved from http://www.bartintl.com/content/simcom-pks-sim-bay3909rsjpg Reprinted with permission.)

\section{Disadvantages}

Extensive simulator use for training does have some drawbacks, however. Some disadvantages of simulators include (a) simulator sickness, (b) inducing adaptation and compensatory skills, (c) poor motion cueing, (d) lack of user motivation, (e) a complex system architecture, (f) over-regulation, and (g) high costs associated with the most advanced simulators (Lee, 2009). Simulator sickness 
is a form of motion sickness and can occur in both fixed and motion-based simulators. Symptoms exhibited by pilots include sweating, fatigue, dizziness, and vomiting (Lee, 2009). Pilots experiencing simulator sickness can be affected to the point of needing to stop the training (Stein \& Robinski, 2012). Motion cueing, the algorithm used by simulators to align visual input with human motion sensing, is employed on the more advanced machines and is expensive to install and maintain (Williges et al., 2001). This process aims to replicate the feeling of being in a real aircraft. However, poor motion cueing can cause diminished fidelity and increased sickness.

Additionally, subjects know they are not in the aircraft potentially impacting pilot motivation. Their perception of the danger and stress level may be significantly reduced resulting in decisions that would not be made in the aircraft (Lee, 2009). For example, a pilot may elect to continue an unstable approach and attempt to land the aircraft in an unsafe situation. Whereas, if airborne, the decision may have been to go-around. Another disadvantage is the multitude of technical requirements of the simulator, creating a highly complex system architecture. Making changes to the simulator system architecture is often impeded by the plethora of government regulations in the certification process (Lee, 2009). Finally, cost, especially for smaller carriers, is a significant determinant of the level of fidelity that is incorporated into an operator's training program and thus can be an impediment to widespread use of simulators (Lee, 2009).

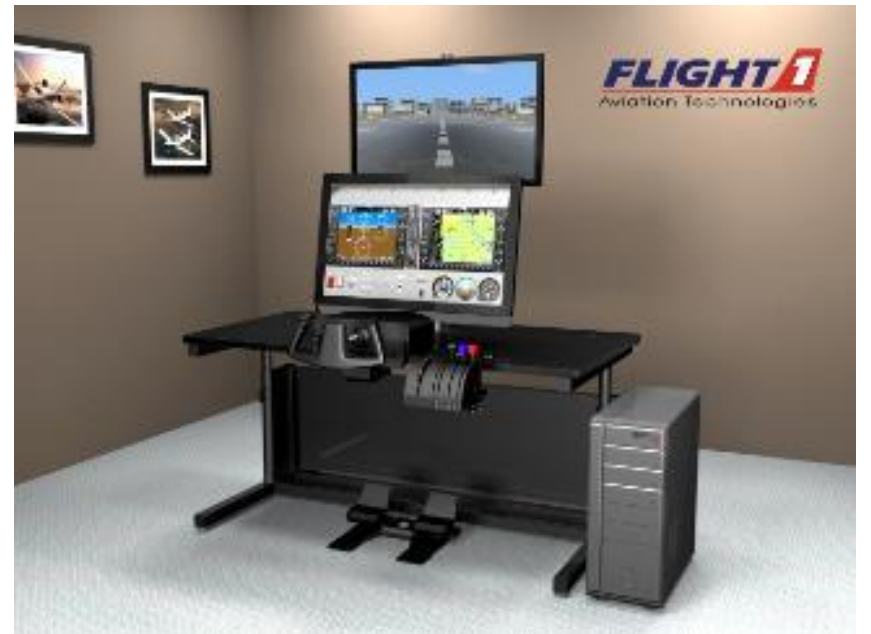

Figure 4. G1000 Part Task-Trainer. (Retrieved from http://www.flight1tech.com/ products/avionicssimulations/garming1000studentsimulatorsoftware.aspx. Flight 1 Tech Systems. Reprinted with permission.) 


\section{Simulator Fidelity - Key Definitions}

Fidelity is a fundamental concept in simulator design and is comprised of three elements: physical fidelity, cognitive fidelity, and functional fidelity. These elements are defined as follows.

Physical fidelity is the level to which the simulator replicates the physical aircraft flight deck and feel (Allen et al, 1986). Physical fidelity includes motion, visual, and sound replication. There are limits to physical fidelity: Schroeder and Chung (2001) and Vaden and Hall (2005) assert, for example, that current motion technology cannot replicate the actual motion cues a pilot would receive in coordinated flight to a $100 \%$ level.

Cognitive fidelity refers to the ability of the simulator training environment to replicate the cognitive skills required on the flight deck (Lee, 2009). Specifically, factors that comprise cognitive fidelity include psychological and perceptive factors such as situational awareness, anxiety, stress, and decision making (Taber, 2014).

Functional fidelity is defined as to what degree the simulator acts like the real equipment (Allen et al., 1986).

Another important definition related to fidelity is task, which is a goal or problem to be solved (Lintern, 2001). It is important to distinguish between a simulator and trainer as well. A simulator is a device that represents a specific counterpart aircraft whereas a trainer represents a particular class of vehicles (Williges et al., 2001).

Havighurst, Fields, and Fields (2010) define high fidelity as the required equipment and materials necessary to adequately simulate the task the learner is expected to perform. They define low fidelity as equipment and materials that are less similar to what task the learner is expected to perform.

Self-efficacy is the belief in one's capabilities to correctly perform a task. Generally, high-perceived self-efficacy can lead to positive performance outcomes (Holbrook \& Cennamo, 2014). 


\section{High-fidelity Simulators}

High-fidelity simulators have been shown to increase self-efficacy (Holbrook \& Cennamo, 2014). Taber (2014) reinforces this point stating that reducing simulator capability to the minimum level impedes confidence in future skill performance. This, in turn, impedes the development of necessary coping strategies. Many simulator designers, operators, technicians, and behavioral scientists believe that the simulator should be designed with the maximum fidelity possible since that is postulated to provide the most training transfer. However, doing so results in higher costs that may not be feasible for some organizations (Lintern, Sheppard, Parker, Yates, \& Nolan, 1989).

The final component of understanding the nature of fidelity includes Hays and Singer's (1989) four levels of fidelity. Level 1 is considered high fidelity and includes two aspects: precise reproduction of the operational counterpart and deliberate reduction in fidelity to reduce costs without compromising training effectiveness. The other three levels have incremental reductions in the level of fidelity (Hays \& Singer, 1989). For this paper, fidelity refers to the extent to which the training situation must be similar to the actual aircraft situation in order to provide effective training.

The development of high fidelity simulators requires the ongoing engagement of stakeholders throughout the process. Naweed, Ward, Gourlay, and Dawson (2017) suggest cross-disciplinary teams with a transdisciplinary approach are most beneficial. This allows for sharing of knowledge and innovation from one field to another. Such practices, they argue, supports this collaboration where teams are better able to anticipate challenges, formulate resolutions, and establish more innovative responses to promote fidelity of simulators (Naweed et al., 2017).

\section{Simulator Fidelity and Transfer of Training}

There is considerable debate regarding the effect of simulator fidelity on training transfer, particularly regarding the impact of motion on training transfer. When performance in the aircraft is better than if there was no simulator training provided, this is called positive training transfer. Conversely, negative training transfer refers to those situations when performance in the aircraft is poorer than if there was no pre-training at all (Listern, 2001). Several studies concluded that low fidelity resulted in negative training transfer, while other studies concluded that the degree of simulator fidelity had little or no effect on training transfer, making the subject contentious among training experts (Listern, 2001). 
When considering training transfer, it can be further divided into three subareas: self-transfer, near transfer, and far transfer. Self-transfer is the decrement or improvement in training transfer resulting from the repeated practice of the same event. Near transfer is the decrement or improvement in training transfer resulting from practicing different but similar events. Far transfer is the decrement or improvement in training transfer resulting from the repeated practice of dissimilar events (Noble, 2002).

\section{The Debate}

\section{Simulator Fidelity Does Not Affect Training Transfer}

Studies regarding simulator fidelity are inconclusive and, at times, seemingly contradictory, with many asserting fidelity does not affect training transfer while others affirm impacts. Burki-Cohen, Go, and Longridge (2001) researched engine failure scenarios that resulted in either a rejected take-off or continued take-off. They concluded from their study that motion for these tasks did not affect evaluation and training simulator progress or transfer of training. The authors, while exploring fidelity background information, did note that motion improved pilot performance and control behavior when performing disturbance and tracking tasks for low stability aircraft in the simulator (Burki-Cohen et al, 2001).

Norman, Dore, and Grierson (2012) in a study of medical students performing clinical tasks in high-fidelity and low-fidelity simulators concluded that there was no significant advantage (average differences $11 \%$ to $2 \%$ ) of the highfidelity simulator use over the low-fidelity simulator. In a similar study, Fraser, Peets, Walker, Tworek, Paget, Wright, and McLaughlin (2009) conducted a medical students' training study using a cardiorespiratory simulator (CRS). While the simulator improved results when compared to students who did not use a simulator, students displayed only a limited ability to transfer skills learned to other real-world problems (Fraser et al, 2009).

Lintern et al. (1989) note in their study of ground attack bombing that decreasing physical fidelity does not always lead to a decrease in training transfer. Specifically, there was no difference in performance among crews using three different visual simulation fields of view (Litern et al, 1989; Williges et al., 2001). The researchers specifically mention, however, that visual simulation is needed for ground-referenced maneuvers where high danger is present, such as high-speed/low

altitude military operations. They advocate that as learning changes, more experience is gained (Lintern et al., 1989; Williges et al., 2001). Thus, fidelity 
requirements change as learning progresses. Additionally, fidelity requirements will also change based on learner ability and skill.

In a study of engine failure scenarios on takeoff, it was noted that no significant training transfer differences between pilots who used motion and those who did not. In the same study, however, the authors note that a lack of fidelity in Air Traffic Control (ATC) communications offers an incomplete cognitive environment and creates a false sense of simplicity to the pilots (Bürki-Cohen, Boothe, Soja, DiSario, Go, \& Longridge, 2000). This viewpoint is echoed by Lee (2009) who stated that sound provides pilots needed feedback on both aircraft systems and ATC communications to more fully simulate the aircraft operating environment.

Vaden and Hall (2005) concluded that simulator performance and the follow-on transfer performance did not show a direct relation. Additionally, empirical evidence supporting the use of motion to improve training transfer is lacking. Conclusions from the researchers cited in Vaden and Hall's (2005) study include the following:

- A comparison of T-37 pilot training students who used motion and those who did not use motion yielded no practical or statistical differences

- In a study of T-2C aircraft landings, motion was found to provide no statistical benefit

- In a study of F-16 maneuver training in a fixed versus motion simulator, there were no significant statistical differences in performance, although it was noted that motion tended to improve performance in some areas and degraded it in others

Neither field of view nor scene detail influenced training transfer from the simulator to the aircraft (Caretta \& Dunlap, 1998; Lintern \& Garrison, 1992; Lintern et al., 1997). Dahlström (2008) in a study of pilot training students up to the first solo offered the following conclusions:

- High fidelity simulation has not necessarily resulted in improved opportunities for learning coordinative and cognitive skills

- Despite high pilot acceptance, convincing visual effects, and apparent validity of high-fidelity simulators, there is no certainty as to whether training quality is improved

- With the introduction of new technology, operator work demands are changed and new ways of performance and possibilities for new forms of accidents can surface 
- To equate fidelity with better training reflects a limited view on training

\section{Simulator Fidelity Does Affect Training Transfer}

Though many findings suggest no impact on training transfer by fidelity, much research suggests fidelity does have an effect. Holbrook and Cennamo (2014) in their study of high-fidelity and self-efficacy with law enforcement officers found that high fidelity increased self-efficacy, emotional arousal, and led to positive training transfer from the lessons learned in the simulator scenarios. The study subjects remarked that no previous experience had prepared them as well as this simulator period. Additionally, they commented that there was no experience better than this because the simulator scenarios were so realistic (Holbrook \& Cennamo, 2014).

A study of platform-based simulator motion concluded that, for pilot coordinated maneuvers, the motion platform must translate laterally when it rolls. If not, the pilot feels an uncoordinated turn and the needle and ball indicate a slip (Schroeder \& Chung, 2001). The study determined that as the motion cues degraded, both objective and subjective evaluation results worsened (Schroeder \& Chung, 2001).

Testing Boeing 747-400 Captains and First Officers in four maneuvers, including both engine failure scenarios during takeoff and engine-out landing maneuvers, Burki-Cohen et al. (2003) determined the advantage of motion fidelity was small for the engine failures on takeoff. However, the results demonstrated the early alerting function of motion (Burki-Cohen et al., 2003). In the other maneuvers, only very slight differences were noted, such as the motion group had slightly longer and softer landings than the non-motion group. No difference in performance was noted during recurrent evaluations indicating there was no benefit for recurrent training (Burki-Cohen et al., 2003).

Advocating that the closer the simulation is to real-world conditions, the better the transfer of skills, it was found that a high level of cognitive and physical fidelity was required for Helicopter Underwater Egress Training (programs) (Baldwin \& Ford, 1988; Hochmitz \& Yuviler-Gavish, 2011; Taber, 2014). Doing so provides individuals the ability to practice whole-task skill demonstration in several critical areas and provides the best transfer of training.

Bürki-Cohen et al. (2000) in their study noted that in an FAA-sponsored review of AC120-40B, Subject Matter Experts (SMEs) from industry, the FAA, 
and academia generally perceived the absence of motion to likely have detrimental effects on pilot control performance. This is especially true when performing maneuvers where sudden motion onset cueing with limited visual references occur.

Motion is necessary for correct control inputs, especially for maneuvers that involve high-G tolerance and spatial disorientation avoidance (Viden \& Hall, 2005). Specifically, during training, trainees who receive no-motion training can never achieve the same performance level as those with motion training. They conclude:

- If pilot performance is dependent on motion in flight, then the simulator with motion will provide better transfer than the simulator without motion

- A lack of motion caused trainees to be less successful in developing flight control strategies than those trainees who had practiced the skill with motion

- Generally, student pilot and instructor feedback indicate that including motion provides greater simulator acceptance and meets pilot performance expectations

- Pilots preferred motion to no motion when the task was to control an unstable aircraft

- In a study of helicopter coupled-hover departure procedures, motion was found to have a positive statistical effect on pilot performance (Viden \& Hall, 2005)

For high-altitude stall recovery and overbank recovery, motion improved results in vertical motion simulators (Zaal, Schroeder, \& Chung, 2015). Additionally, simulation motion needs to be intense and abrupt enough to provide the appropriate stimulus that the pilot can detect and input an appropriate control response (Caro, 2001a). Pilot survey ratings of motion support this assertion (Zaal et al., 2015). In approach and landing with sidestep and engine out on takeoff, little difference was noted in training transfer (Zaal et al., 2015).

Those trainees who were trained with simulators that had highphysical/high-functional fidelity or high-physical/medium-functional fidelity were found to repeat assigned tasks less frequently (Allen, Hays, \& Buffardi, 1986). In contrast, the highest number of required repeated attempts occurred for those trainees who were using medium-function/low-physical fidelity simulators. Thus, the authors concluded that both functional and physical fidelity had a strong effect on performance. Additionally, lower physical fidelity was associated with longer solution times. Finally, they concluded that given the physical and functional 
fidelity relationships discovered, functional and physical fidelity should not be dealt with in isolation (Allen et al., 1986).

Allen, Park, and Cook (2010), in their study on simulator driving scenarios, found that those subjects training in a cab with a full-sized projected image had the lowest crash rate and exhibited the least aggressive driving behavior. However, the authors note several confounding variables were present which could have affected the results.

Noble (2002) in his study, concluded that learner skill level must be considered when determining fidelity. As the learner skill level improves, lowquality fidelity devices become less effective when one considers the cost to build them versus training efficiency. The learning stage of the student, the goals of the training, and the level of fidelity are not mutually exclusive. Additionally, Noble (2002) concluded from a study of KC-135 boom operators using a Boom-Operator Part-Task Trainer (BOPTT), that both the environment and the task must be considered when studying training transfer.

Hochmitz and Yuviler-Gavish (2011) conducted a simple study that divided respondents into two groups consisting of a physical fidelity group and a cognitive fidelity group. A three-dimensional virtual simulator was used. Performance measures included training time, number of final errors, test time, number of corrected errors, and time used to correct errors. The authors concluded that for development of procedural skills in psychomotor tasks, a training approach using both cognitive and physical training was required.

Lintern (2001) in his study concluded that skill transfer was based on some type of similarity between the operational and training experience. His basic premise is that the level of transfer is based on the extent to which the two environments share common components.

\section{Simulator Fidelity Training Transfer}

After examining the various studies, the contradictory results of training transfer were found to be caused primarily by lack of clearly defined study methodologies, variances in study methodologies, and variances in the individual tasks studied. Several authors note the study methodology problems (Caretta \& Dunlap, 1998; Vaden \& Hall, 2005). Besides methodology problems, Caretta and Dunlap (1998) also highlight lack of understanding of the mission and lack of true simulator-to-aircraft transfer studies as contributors to conflicting results. Other variables found to significantly influence results of studies include (a) criterion 
measures where subjective measurements are used, (b) the subjects who have different motor skills and cognitive capabilities, and (c) the instructor, who plays an important role because of biases, attitudes, motivation, and abilities (Valverde, 1973).

It is understandable that results varied as often the specific tasks studied also varied from study to study. For example, for upset recoveries, such as American Flight 587, the NTSB, FAA, and other authors (Munshi, Lababidi, \& Alyousef, 2015; Vaden \& Hall, 2005; Zaal et al., 2015) agree that high fidelity is needed. For a task, such as being able to locate a switch in the cockpit, a part-task trainer consisting of a cockpit diagram pasted on a piece of cardboard may suffice. However, part-trainers are limited in their use (Caro, 2001b).

Ultimately, the amount of fidelity needed is specific to the training objective, the individual task being trained, and the learning level of the student (Caretta \& Dunlap, 1998; Lee, 2009). Blaiwes et al. (2001) support this assertion and further support the variance in study results. Different flight task types transfer differently (Blaiwes et al., 2001). Further, Blaiwes et al. (2001) conclude (a) particular motion types affect trainee training transfer and performance, (b) the level of fidelity and type of trainer notably influences transfer, and (c) careful specification of operational and trainer tasks is necessary to maximize training transfer.

Finally, the FAA provides regulatory guidance through the Advanced Qualification Program (AQP), Advanced Simulation Plan (ASP) and Advisory Circular (AC)120-40b on simulator fidelity (Burki-Cohen, Go, \& Longridge, 2001; FAA, 2017). The AQP is designed to respond to changing training needs providing pilots who not only have the requisite knowledge and hands-on skill but also are proficient integrating cognitive and motor skills. The FAA is committed to effectively preparing pilots to carry passengers. Thus, simulators must represent the motor and cognitive challenges that would be experienced in an operational environment. Additionally, the simulators must be sufficient to ensure full transfer of performance and behaviors that would be experienced in the air (Burki-Cohen, et al., 2001). To change regulatory guidance regarding fidelity, consistent study results must present unequivocal evidence to prove that high-fidelity is not required for the individual tasks in question (Bürki-Cohen, et al., 2000).

\section{Safety and Fidelity}

Improved safety outcomes are among the key factors in desiring appropriate 
fidelity within training environments. To better understand the relationship between safety and simulator fidelity, a search was conducted of the NTSB website for safety recommendations that included the word simulator for the aviation transportation mode. The search returned 37 results that consisted of 29 recommendations for procedure changes and 8 fidelity improvements. These recommendations are the result of commercial or business aircraft mishaps and are summarized chronologically below:

Eastern Airlines Flight 66. On June 24, 1975, Flight 66, a Boeing 727, crashed while executing a precision approach to John F. Kennedy Airport in Jamaica, New York, killing 113 people. The aircraft was flying through or at the base of a mature thunderstorm. The NTSB recognized that from this mishap and other mishaps, thunderstorms were a problem. Therefore, the NTSB recommended that wind shear models be developed for simulators to train pilots on the effects of mature thunderstorms (NTSB, 1976).

Pan Am Flight 759. On July 9, 1982, Flight 759 crashed while taking off from New Orleans International Airport in Kenner, Louisiana, killing 145 people on the aircraft and 8 people on the ground. Windshear conditions had been detected by the airport just prior to takeoff and there were heavy rain showers on the departure path. Because of this mishap and other mishaps involving wind shear, the NTSB recommended that realistic microburst wind models be incorporated into flight simulator training programs (NTSB, 1982).

Rejected Takeoffs. After a series of mishaps related to high-speed rejected takeoffs, the NTSB issued two safety recommendations: A-90-043 and A-90-044. As part of the A-90-043 recommendation, the NTSB required, to the maximum extent possible, that cues and cockpit warnings that resulted in high speed rejected takeoffs for other than engine failures be incorporated. An example would be a tire failure during takeoff. Additionally, A-90-044 required that all simulators of passenger carrying operators accurately produce stopping distance available for a rejected takeoff (NTSB, 1990).

China Eastern Airlines, flight 583. On April 6, 1993, Flight 583 was flying from Beijing to Los Angeles when the slats inadvertently deployed during cruise flight. The Captain flew the aircraft through several violent pitch oscillations and lost 5,000 feet. Two passengers were fatally injured and 149 passengers and 7 crewmembers were injured to some degree. As a result of the mishap, the NTSB recommended that the Douglas Aircraft Company provide data needed to upgrade the MD-11 simulators to accurately represent the longitudinal stability and control characteristics of the aircraft (NTSB,1993). 
U.S. Airways Flight 427. September 8, 1994, Flight 427, a Boeing 737, crashed while maneuvering to land at the Pittsburgh International Airport in Pittsburgh, Pennsylvania. The aircraft descended uncontrollably and impacted the terrain killing all 132 people on board and destroying the aircraft. The cause of the mishap was an un-commanded rudder reversal which caused the aircraft to depart controlled flight. In the mishap report, the NTSB stated that the simulator characteristics developed by Boeing and implemented by air carriers in simulators did not adequately represent the crossover airspeed phenomenon and suggested that the fidelity be addressed since data is readily available from flight tests (NTSB, 1999).

Tower Air Flight 41. December 20, 1995, Flight 41, a Boeing 747, veered off the left side of the runway while taking off from John F. Kennedy Airport in Jamaica, New York. There were no fatalities, but 24 passengers received minor injuries, one flight attendant received serious injuries, and the aircraft sustained substantial damage. The primary cause of the mishap was the failure to reject the takeoff after loss of directional control. The NTSB stated their concern with the inability of pilots to attain needed training for slippery runway procedures due to poor simulator fidelity. They also found that while the Boeing simulators provided a more accurate model, the air carrier simulators did not. Thus, the NTSB concluded that improvements in slippery runway handling fidelity in 747 flight simulators were both needed and feasible (NTSB, 1996).

Airborne Express. On December 22, 1996, an Airborne Express Douglas DC-8 crashed into mountainous terrain near Narrows, Virginia. The three crewmembers and three maintenance personnel on the functional check flight were killed and the aircraft was destroyed. The primary cause of the mishap was improper applied control inputs during a stall recovery attempt. The NTSB evaluation of the simulator fidelity found that the simulator did not produce the stall characteristics of the DC-8 with adequate fidelity. Thus, the crew was provided with a misleading expectation of the aircraft's handling characteristics. The NTSB recommended the FAA evaluate all simulator stall characteristics in air carrier simulators and change them as necessary to represent to the maximum extent possible the stall characteristics of each aircraft (NTSB, 1997).

Global Exec Aviation Bombardier Learjet Model 60. On September 19, 2008, a Bombardier Learjet overran the runway during a rejected takeoff at the Columbia Metropolitan Airport in Columbia, South Carolina. Two passengers, the Captain, and the First Officer were killed and two other passengers were seriously injured. The right main landing gear tire had separated from the wheel causing 
vibration and shaking of the airframe and subsequent failure of the three main landing gear tires during the attempted takeoff rejection. As part of the recommendation to provide realistic tire failure training, the NTSB recommended that the FAA define and codify minimum simulator fidelity for tire failure scenarios (NTSB, 2010).

Based on their analysis, it is clear the NTSB considers simulator fidelity in certain tasks a fundamental requirement to safely execute flight maneuvers. These eight examples offer insight into mishaps where simulator fidelity, while not a direct cause of the accident, was identified as a contributing factor. If improved, simulator fidelity may well help prevent similar occurrences. Some industry stakeholders and researchers would assert that since commercial aviation is remarkably safe and instances of negative transfer from simulators are rare, the risk of maintaining the status quo is acceptable. Conversely, it could be argued that between just the eight mishap recommendations listed above, 410 lives were lost and that is unacceptable. The moral dilemma is determining the correct balance between cost-effectiveness and safety. These eight safety recommendations made by the NTSB, however, reinforce that the agency views increased fidelity as a fundamental requirement in enhancing safety. One such way to do so is to understand the ways in which the instructor may impact training transfer.

\section{The Instructor's Role in Maximizing Training Transfer}

The simulator training process is made of three parts that include (a) the simulator, (b) the training syllabus and associated objectives, and (c) the instructor (Lee, 2009). The simulator itself does not train, as it is simply a tool used in the training process. Simulator design and flight training syllabi development receive significant attention from various stakeholders. The instructor, however, is often overlooked in this process despite the role of the instructor as a key element in the success of training (Lee, 2009). It was found that a flight instructor influenced the student's progress more than syllabi variations or the simulator (Valverde, 1973). In the most recent AC 120-54A, Advanced Qualification Program, considered the agency's most advanced and dynamic training system, the FAA asserts in the section Instructors and Evaluators that "Instructors, evaluators, and supervisors are the backbone of the Advanced Qualification Program” (FAA, 2017, p. 63).

The simulator instructor has many duties and plays many roles. The instructor must be familiar with simulator capabilities and limitations, know the lesson objectives, and instruct to attain the best performance from individual students who vary in attitude, hands-on skill level, and cognitive ability (Lintern et al., 1989). The instructor's role is to obtain the highest performance possible from 
the student for a task while optimizing the time in the simulator period to do so. Simulator instructors must also be familiar with and role-play air traffic controllers, ground/dispatch/maintenance personnel, and other crew positions throughout numerous training scenarios.

It is imperative that the instructor identify the differences between the simulator and the aircraft to prevent known simulator deficiencies from creating a negative training transfer. This requires an extensive knowledge of and/or experience in the actual aircraft to be able to discern the differences (Lintern et al., 1989). The fidelity gaps must be filled in by instructing the students on the deficiencies of the simulator. Caro (2001a) concluded from his pilot training study that the instructors tended to concentrate on procedural task during simulator training and not emphasize the training value of the simulators regarding dynamic flight tasks.

Additionally, if the trainee develops a negative attitude toward the simulator and instruction, the attitude may carry over to the aircraft (Valverde, 1973). As such, the instructor's attitude toward the simulator capabilities must remain positive to elicit an increase in psychological fidelity and to improve self-efficacy (Valverde, 1973). Blaiwes et al. (2001), in their study of the transfer of training and measurement of training effectiveness, echo this conclusion. How a device is used may influence transfer and learning to a higher degree than trainer design (Blaiwes et al., 2001).

The instructor's role in minimizing the disadvantages of the simulator are key to a successful training transfer (Lee, 2009). The most significant disadvantage, simulator sickness, requires the instructor to be knowledgeable on the circumstances that cause simulator sickness, the symptoms of it, and how to minimize the effects of simulator sickness by effectively using motion. Further, motion cueing should only be used when the training task dictates to minimize maintenance breakdowns and simulator sickness (Lee, 2009).

Adaptation and compensatory skills will be required to some degree from the pilots. The instructor must communicate to the pilots the differences in simulator and aircraft performance so pilots can be familiar with the differences and not be surprised when operating the aircraft (Lee, 2009). If the adaptation and compensatory skills are excessive, the instructor has the obligation to report those discrepancies to maintenance and/or pilot training management personnel for further action. To enhance user motivation, the instructor can point out the advantages of the simulator, encourage pilots to take advantage of the training opportunity to hone their skills, and maintain a positive attitude concerning simulator capabilities to the student pilots. By using various features of the 
simulator such as the reposition function, the instructor can optimize time in the trainer and reduce the overall training costs (Lee, 2009).

It is sometimes advocated to use part-task trainers as a cost savings measure and these seem to have some utility in initial training. However, as noted by Williges et. al. (2001), training using only part-task trainers results in pilots not having the opportunity to practice time-sharing attention among the many tasks required on the flight deck. The simulator, the training syllabi and associated objectives, and the instructor must work in harmony for the training to be effective (Lee, 2009). Quality simulators alone cannot provide adequate training to students with recent studies suggesting the degree of fidelity within a simulator is independent of training efficacy. Rather, high fidelity within simulators is most associated with positive training outcomes where systematic integration through quality instructional programming allows for learner engagement as well as the suspension of disbelief (Hamstra, Brydges, Hatala, Zendejas, \& Cook, 2014).

To evaluate simulator effectiveness, Lee (2009) developed the Transfer Effectiveness Ratio (TER). It uses a formula: TER $=(\mathrm{A}-\mathrm{AS}) / \mathrm{S}$, where $\mathrm{A}$ is the aircraft training time not including simulator training, $\mathrm{S}$ is the simulator training time, and AS is total training time. A positive result indicates positive training transfer while a negative result represents negative training transfer. However, the results can be skewed towards the positive if the instructor rapidly repositions and reconfigures the simulator (Lee, 2009). This practice is commonly utilized in simulator training to optimize training time. Additionally, conducting the study to derive the needed information to determine the values of the equations can also be problematic. As such, one equation is not enough when evaluating the effectiveness of a training device.

Williges et al. (2001) assert more aspects are required, listing three criteria necessary for evaluating a training device: (a) how effective the current learning is, (b) the learning transfer from one situation to another, and (c) learning retention. The optimal solution is for academia, training departments, examiners, and the FAA to agree on the goals and expectations of simulator fidelity related to specific tasks (Noble, 2002). It should be remembered that the primary purpose of the simulator is not to replicate the exact physical representation of the flight deck, but instead to create the experience of the flight environment and provide a realistic and economical training platform (Lee, 2009). 


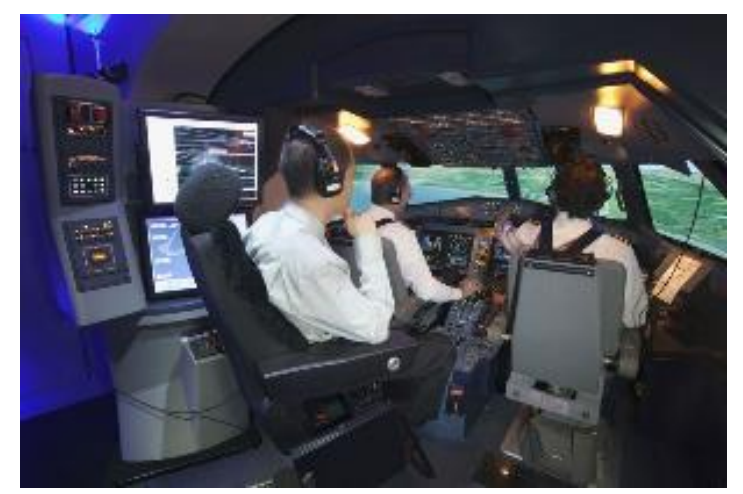

Figure 5. ATR 600 Flight Simulator with Instructor Station. (Retrieved from http://www.ainonline.com/sites/default/files/uploads/2014/02/500-ain-sing-atrtraining-sim-in-singapore-1.jpg. Courtesy of AIN. Reprinted with permission.)

\section{Instructional Design Models and the Role of the Instructor}

On a final note, it is important to consider that the simulator instructor is on the delivery end of the instructional design model. The objectives, content, delivery schedule, and other instructional components have been largely developed, approved and, in many cases, codified into FAA requirements and practices. This leaves the simulator instructor with little control over course content. To provide the best possible products to the instructor for utilization in training, current best practices for instructional design must be employed. Dozens of respected instructional design models may be employed throughout various factions of the aviation training industry. Among the most commonly used and research-supported models, particularly in training environments, are Gagne's nine learning events and John Keller's motivational ARCS model.

Gagne's (1970) nine steps of instructional design include (a) gaining attention, (b) informing the learner of the objectives, (c) stimulating recall prior to learning, (d) presenting stimulus, (e) providing learning guidance, (f) eliciting performance, $(\mathrm{g})$ providing feedback, (h) assessing performance, and (i) enhancing retention and transfer. Let us consider this model in a simulation training environment, including the pre-brief, simulator training, and debrief as shown in Table 1.

In conjunction with Gagne's nine-step instructional design process, other models may be employed. John Keller's motivation-based ARCS model, commonly utilized for adult learners, provides an adjustment for those learners who constantly live in an accelerated and multi-task mode (Afip, 2014). ARCS, short for (a) attention, (b) relevance, (c) confidence, and (d) satisfaction, is designed to 
supplement the learning process by stimulating and sustaining the learner's motivation to learn (Afip, 2014).

Table 1

Gagne's Nine Step Model Applied to Simulator Training

\begin{tabular}{|l|l|l|}
\hline Pre-Brief & Simulator & Debrief \\
\hline $\begin{array}{l}\text { Steps a, b, and c are } \\
\text { presented in the } \\
\text { simulator pre-brief } \\
\text { where the simulator } \\
\text { profile is reviewed and } \\
\text { students are queried on } \\
\text { knowledge. }\end{array}$ & $\begin{array}{l}\text { Steps d, e, f, and g are } \\
\text { accomplished in the } \\
\text { simulator. The stimulus } \\
\text { presented, step d, is the } \\
\text { simulator and tasks } \\
\text { assigned. Learning } \\
\text { guidance, step e, is } \\
\text { provided by the } \\
\text { instructor who provides } \\
\text { coaching as required to } \\
\text { accomplish the tasks. } \\
\text { instructor who provides } \\
\text { feedback to the students } \\
\text { on their performance, } \\
\text { with guidance as to how } \\
\text { to improve the } \\
\text { performance if } \\
\text { warranted. Steps g, h, } \\
\text { and i are accomplished } \\
\text { during the simulator } \\
\text { debrief. Students are } \\
\text { provided more feedback } \\
\text { on their performance, } \\
\text { by instructor who } \\
\text { provides the instruction } \\
\text { and motivation to the } \\
\text { students to accomplish } \\
\text { and techniques are } \\
\text { the tasks. }\end{array}$ \\
& \multicolumn{2}{|l}{$\begin{array}{l}\text { provided as to how to } \\
\text { best retain and learn the } \\
\text { information or tasks. }\end{array}$} \\
\hline
\end{tabular}

Attention refers to the level of interest taking in ideas and concepts. Usually, attention is obtained by either perceptual or inquiry arousal. Ensuring the instruction and topic are pertinent to the learners comprises the relevance portion (Afip, 2014). This is generally accomplished by using clear language and examples the learner is familiar with. Confidence is achieved by establishing a learner's positive expectation for achieving success. Establishing confidence can be achieved by specifying performance requirements and learning standards. Concerning satisfaction, the idea is for the learners to obtain satisfaction or reward from the learning experience (Afip, 2014). Feedback and reinforcement are key elements to achieve this goal.

Employing well-validated methods of instructional design geared towards the typical audience within simulators allows instructors to better engage with their students. This engagement can lead to increased training transfer as well as 
improved outcomes as instruction relates to fidelity within simulators. Where instructors have the platform to discuss the nuances of a particular simulator and adjust their methods to meet those needs, learners will better understand how the experience in the simulator relates to the real experience.

\section{Recommendations for Further Research}

The authors suggest the following expansions for further research into the realm of simulator fidelity and instruction. First, future FAA research should focus on implementing current best practices with elements of established models such as Gagne's nine learning events and John Keller's motivational ARCS model. In addition, all stakeholders should coordinate further research to determine fidelity shortfalls for simulator tasks that may be specific to each aircraft or maneuver. Finally, this study does not address the unique differences in motion and nonmotion simulation as they relate to fidelity, training transfer, and the role of instructors. As such, the authors suggest this as an important avenue for further research.

\section{Conclusion}

As established in the literature, fidelity is a difficult concept to attain agreement on, particularly when one considers the various levels of fidelity that may be present within the same simulator depending on the task performed. Further, despite copious research regarding simulation and fidelity, relatively few studies on the instructor's roles, responsibility, and their overall impact on the training product have been conducted. Current research and assessment practices were evaluated with recommendations for incorporating instructional design (ISD) principles and identifying and instructing fidelity shortfalls. This was done to explore the flight simulator instructor's role in exploiting the simulator's strengths as a training tool while minimizing negative training transfer. It is proposed that ISD practices will ensure simulator instructors are provided with the most current and appropriate teaching tools. These improvements, along with standardized research methods analyzing fidelity will optimize valuable simulator time and ensure students are getting the best possible training to take back to the aircraft. 


\section{References}

Afip, L. B. A. (2014). Motivating Adult Learners Using Blended Learning in Higher Education Institution. Researchers World, 5(3), 35-42.

Allen, J. A., Hays, R. T., \& Buffardi, L. C. (2001). Maintenance training simulator fidelity and individual differences in transfer of training. In R. Sweezey, \& D. Andrews (Eds.), Readings in training and simulation: a 30-year perspective (pp. 272-284). Santa Monica, CA: Human Factors and Ergonomics Society. doi: 10.1177/001872088602800501

Allen, R., Park, G., \& Cook, M. (2010). Simulator fidelity and validity in a transfer of-training context. Transportation Research Record: Journal of the Transportation Research Board, 2185, 40-47. doi:10.3141/2185-06

Blaiwes, A. S., Pug, J. A, Regan, J.J., (2001). Transfer of training and the measurement of training effectiveness. In R. Sweezey, \& D. Andrews (Eds.), Readings in training and simulation: a 30-year perspective (pp. 2 12). Santa Monica, CA: Human Factors and Ergonomics Society. doi: $10.1177 / 001872087301500604$

Bürki-Cohen, J., Boothe, E. M., Soja, N. N., DiSario, R. D., Go, T., \& Longridge, T. (2000, May). Simulator fidelity: The effect of platform motion. In proceedings of the Royal Aeronautical Society conference on Flight Simulation-The Next Decade, London.

Burki-Cohen, J., Go, T. H., \& Longridge, T. (2001, August). Flight simulator fidelity considerations for total airline pilot training and evaluation. In Proc. of the AIAA Modeling and Simulation Technologies Conference.

Caro, P., (2001a). Aircraft simulators and pilot training. In R. Sweezey, \& D. Andrews (Eds.), Readings in training and simulation: a 30-year perspective (pp. 2-12). Santa Monica, CA: Human Factors and Ergonomics Society. doi: 10.1177/001872087301500602

Caro, P., (2001b). The relationship between flight simulator motion and training requirements. In R. Sweezey, \& D. Andrews (Eds.), Readings in training and simulation: a 30-year perspective (pp. 2-12). Santa Monica, CA: Human Factors and Ergonomics Society. doi: 10.1177/001872087902100411 
Dahlström, N. (2008). Pilot training in our time - use of flight training devices and simulators. Aviation, 12(1), 22-27. doi:10.3846/1648-7788.2008.12.22-27

Federal Aviation Administration (FAA). (2017). Advanced qualification program. FAA Advisory Circular (AC 120-54A). Retrieved from https://www.faa.gov/regulations policies/advisory_circulars/index.cfm/go/document.information/document ID/23190

Fraser, K., Peets, A., Walker, I., Tworek, J., Paget, M., Wright, B., \& McLaughlin, K. (2009). The effect of simulator training on clinical skills acquisition, retention and transfer. Medical Education, 43(8), 784-789. doi:10.1111/j.1365-2923.2009.03412.x

Gagne, R.M. (1970). The conditions of learning. New York, NY: Holt, Rinehart, and Winston.

Hamstra, S.J., Brydges, R., Hatala, R., Zendejas, B., \& Cook, D.A. (2014). Reconsidering fidelity in simulation-based training. Academic Medicine, 89(3), 387-392. doi: 10.1097/ACM.0000000000000130

Havighurst, L.C., Fields, L.E., \& Fields, C.L. (2003). High versus low fidelity simulations: does the type of format affect candidate's performance or perceptions. In proceedings from the $27^{\text {th }}$ annual IPMAAC conference on personnel assessment, (pp. 22-25).

Hays, R. T., \& Singer, M. J., (1989). Simulation fidelity in training system design bridging the gap between reality and training. New York, NY: Springer Verlag.

Hochmitz, I., \& Yuviler-Gavish, N. (2011). Physical fidelity versus cognitive fidelity training in procedural skills acquisition. Human Factors, 53(5), 489. doi:10.1177/0018720811412777

Holbrook, H. A., \& Cennamo, K. S. (2014). Effects of high-fidelity virtual training simulators on learners' self-efficacy. International Journal of Gaming and Computer-Mediated Simulations (IJGCMS), 6(2), 38-52. doi:10.4018/ijgcms.2014040104

Lee, A.T., (2009). Flight simulation virtual environments in aviation. Burlington, VT: Ashgate. 
Lintern, G. (2001). An informational perspective on skill transfer in human machine systems. In R. Sweezey, \& D. Andrews (Eds.), Readings in training and simulation: a 30-year perspective (pp. 2-12). Santa Monica, CA: Human Factors and Ergonomics Society. doi: $10.1177 / 001872089103300302$

Lintern, G., Sheppard, D. J., Parker, D. L., Yates, K. E., \& Nolan, M. D. (1989). Simulator design and instructional features for air-to-ground attack: A transfer study. Human Factors: The Journal of the Human Factors and Ergonomics Society, 31(1), 87-99. doi: 10.1177/001872088903100107

Longridge, T., Bürki-Cohen, J., Go, T. H., \& Kendra, A. J. (2001, March). Simulator fidelity considerations for training and evaluation of today's airline pilots. In Proceedings of the 11th international symposium on aviation psychology (p. 7).

Longridge, T. M. (1997). Overview of the advanced qualification program. Proceedings of the Human Factors and Ergonomics Society Annual Meeting, 41(2), 898-901. doi:10.1177/107118139704100240

Munshi, F., Labaidi, H., \& Alyousef, S. (2015). Low-versus high-fidelity simulations in teaching and assessing clinical skills. Journal of Taibah University Medical Sciences, 10(1), 12-15. doi: 10.1016/j.jtumed.2015.01.008

Naweed, A., Ward, D., Gourlay, C., \& Dawson, D. (2017). Can participatory ergonomics process tactics improve simulator fidelity and give rise to transdisciplinary in stakeholders? A before-after case study. International Journal of Industrial Ergonomics. In press. doi: 10.1016/j.ergon.2017.07.011.

National Transportation Safety Board. (1976). Eastern Airlines, Boeing 727, Jamaica, New York, July 28, 1982 (Safety Recommendation A76-040). Washington, DC. Retrieved from https://www.ntsb.gov/safety/safetyrecs/_layouts/ntsb.recsearch/Recommendatc ion.aspx?Rec=A-76-040 
National Transportation Safety Board. (1982). Pan American World Airways, Trans World Airlines, Kenner, Louisiana, July 9, 1982, LaGuardia Airport, New York, July 28, 1982 (Safety Recommendation A83-025). Washington, DC. Retrieved from https:///www.ntsb.gov/safety/safetyrecs/_layouts/ntsb.recsearch/Recommendation. aspx?Rec $=\mathrm{A}-83-025$

National Transportation Safety Board. (1990). Multiple Operators, Multiple Locations, (Safety Recommendation A-90-044). Washington, DC. Retrieved from https://www.ntsb.gov/safety/safetyrecs/_layouts/ntsb.recsearch/Recommendation. aspx?Rec=A-90-044

National Transportation Safety Board. (1993). China Eastern Airlines, McDonnell Douglas MD-11, Shemya, Alaska, April 6, 1993 (Safety Recommendation A-93-143). Washington, DC. Retrieved from https://www.ntsb.gov/safety/safety-recs/_layouts/ntsb.recsearch/ https://www.ntsb.gov/safety/safetyrecs/_layouts/ntsb.recsearch/Recommendation.aspx? $\mathrm{Rec}=\mathrm{A}-93-143$

National Transportation Safety Board. (1996). Tower Air, Boeing B-747, Jamaica, New York, December 20, 1996 (Safety Recommendation A-96-153). Washington, DC. Retrieved from https://www.ntsb.gov/safety/safetyrecs/_layouts/ntsb.recsearch/Recommendation. aspx $? \operatorname{Rec}=\mathrm{A}-96-153$

National Transportation Safety Board. (1997). Airborne Express, Douglas DC-8 63, N827AX, Narrows, Virginia, December 22, 1996 (Safety Recommendation A-97-047). Washington, DC. Retrieved from https://www.ntsb.gov/safety/safety-recs/_layouts/ ntsb.recsearch/Recommendation.aspx?Rec=A-97-047

National Transportation Safety Board. (1999). US Airways, Boeing 737-300, N513AU, Aliquippa, Pennsylvania, September 8, 1994 (Safety Recommendation A-99-026). Washington, DC. Retrieved from https://www.ntsb.gov/safety/safety-recs/_layouts/ ntsb.recsearch/Recommendation.aspx?Rec=A-99-026 
National Transportation Safety Board. (2001). American Air Lines, A300-605R, N14053. Dallas-Belle Harbor, New York. November 12, 2001 (Aircraft accident report, NTSB/AAR-89/04). Washington, DC. Retrieved from https://www.ntsb.gov/investigations/Accident Reports/Pages/AAR0404.aspx

National Transportation Safety Board. (2004a). American Airlines, Airbus Industrie A300-605R, Belle Harbor, New York, November 12, 2001 (Safety Recommendation A-04-61). Washington, DC. Retrieved from https://www.ntsb.gov/investigations/AccidentReports/ _layouts/ntsb.recsearch/Recommendation.aspx?Rec=A-04-061

National Transportation Safety Board. (2004b). American Airlines, Airbus Industrie A300-605R, Belle Harbor, New York, November 12, 2001 (Safety Recommendation A-04-62). Washington, DC. Retrieved from https://www.ntsb.gov/investigations/AccidentReports /_layouts/ntsb.recsearch/Recommendation.aspx?Rec=A-04-062

National Transportation Safety Board. (2010). Inter Travel and Services Inc, Bombardier Learjet Model 60, N999LJ, Columbia, South Carolina, September 19, 2008 (Safety Recommendation A-10-055). Washington, DC. Retrieved from https://www.ntsb.gov/ safety/safety-recs/_layouts/ntsb.recsearch/Recommendation.aspx?Rec=A$10-055$

Noble, C. (2002). The relationship between fidelity and learning in aviation training and assessment. Retrieved from https://ntrs.nasa.gov/search.jsp?R=20020074981

Norman, G., Dore, K., \& Grierson, L. (2012). The minimal relationship between simulation fidelity and transfer of learning. Medical Education, 46(7), 636-647. doi:10.1111/j.1365-2923.2012.04243.x

Schroeder, J. A., \& Chung, W. W. (2001). Simulation motion requirements for coordinated maneuvers. Journal of the American Helicopter Society, 46(3), 175. doi:10.4050/JAHS.46.175

Stein, M., \& Robinski, M. (2012). Simulator sickness in flight simulators of the german armed forces. Aviation Psychology and Applied Human Factors, 2(1), 11-19. doi:10.1027/2192-0923/a000022 
Taber, M. J. (2014). Simulation fidelity and contextual interference in helicopter underwater egress training: An analysis of training and retention of egress skills. Safety Science, 62, 271-278. doi:10.1016/j.ssci.2013.08.019

Valverde, H. H. (1973). A review of flight simulator transfer of training studies. Human Factors: The Journal of the Human Factors and Ergonomics Society, 15(6), 510-522. doi:10.1177/001872087301500603

Vaden, E. A., \& Hall, S. (2005). The effect of simulator platform motion on pilot training transfer: A meta-analysis. The International Journal of Aviation Psychology, 15(4), 375-393.doi:10.1207/s15327108ijap1504_5

Williges, B. H., Roscoe, S. N. \& Williges, R. C., (2001). Synthetic flight training revisited transfer of training and the measurement of training effectiveness. In R. Sweezey, \& D. Andrews (Eds.), Readings in training and simulation: a 30-year perspective (pp. 2-12). Santa Monica, CA: Human Factors and Ergonomics Society.

Zaal, P. M. T., Schroeder, J. A., \& Chung, W. W. (2015). Transfer of training on the vertical motion simulator. Journal of Aircraft, 52(6), 1971-1984. doi: 10.2514/1.C033115 